neonatal jaundice: configurational isomers of bilirubin. J Am Chem Soc 104:6865-6867

10. McDonagh AF, Palma LA, Lightner DA 1982 Phototherapy for neonatal jaundice: Stereospecific and regioselective photoisomerization of bilirubin bound to human serum albumin and NMR characterization of intramolecular cyclized photoproducts. J Am Chem Soc 104:6867-6869

11. Lamola AA, Flores J, Doleiden FH 1982 Quantum yield and equilibrium position of the configurational photoisomerization of bilirubin bound to human serum albumin. Photochem Photobiol 35:649-654

12. Costarino AT, Ennever JF, Baumgart S, Speck WT, Paul M, Polin RA 1985 Bilirubin photoisomerization in premature neonates under low and high dose phototherapy. Pediatrics (in press)

13. Lightner DA, Linnane WP'III, Ahlfors CE 1984 Bilirubin photooxidation products in the urine of jaundiced infants receiving phototherapy. Pediatr Res 18:696-700

14. Arant BS 1978 Developmental patterns of renal functional maturation compared in the human neonate. J Pediatr 92:705-712

15. Maisels MJ, Pathak A, Nelson NM, Nathan DG, Smith CA 1971 Endogenous production of carbon monoxide in normal and erythroblastotic newborn infants. J Clin Invest 50:1-8

16. Callahan EW, Thaler MM, Karon M, Bauer K, Schmid R 1970 Phototherapy of severe unconjugated hyperbilirubinemia: formation and removal of labeled bilirubin derivatives. Pediatrics 46:841-848

17. Ennever JF, Sobel M, McDonagh AF, Speck WT 1984 Phototherapy for neonatal jaundice: in vitro comparison of light sources. Pediatr Res 18:667. 670

\title{
The Preterm Rabbit: A Model for the Study of Acute and Chronic Effects of Premature Birth
}

\author{
ANTONIO V. LORENZO
}

Department of Neurosurgery, Children's Hospital, Boston, Massachusetts 02115

\begin{abstract}
The fetal rabbit delivered by caesarean section 0 to 5 days before term ( 32 days) can serve as a reliable animal model to study the short- and long-term consequences of premature birth. More than $80 \%$ of the fetal rabbits delivered at day 28 of gestation will survive $24 \mathrm{~h}$ if anesthetics are avoided during delivery and measures designed to meet the metabolic demands of extrauterine life are met. Sixty percent will survive up to and beyond the 7th day postpartum if the preterm pups are kept in a temperature and humidity controlled environment and are fed rabbit milk. Theoretical and practical advantages of this animal model are discussed. (Pediatr Res 19: 201205, 1985)
\end{abstract}

Laboratory animals delivered before term have been used successfully to study perinatal abnormalities associated with premature birth $(16,17,25)$. However, the inability to prolong survival beyond the first few hours of life has in most instances precluded the use of these animals in chronic studies of prematurity. The poor survival of the premature animal generally has been attributed to difficulties in establishing respiratory function immediately after birth and to the inability to provide effective nurturing postnatally $(4,21,23)$. A notable exception is the nonhuman primate whose ability to survive independently outside the uterus when delivered before term is well documented $(15,26)$. But the relative scarcity and the imposition of new restrictions on the acquisition and expense of monkeys has made the use of these animals in routine laboratory experiments prohibitive. The newborn rabbit delivered before term represents a practical and inexpensive alternative which in addition may be

Received May 29, 1984; accepted October 3, 1984.

Reprint requests to Antonio V. Lorenzo, Ph.D., Department of Neurosurgery, Children's Hospital, 300 Longwood Avenue, Boston, MA 02115.

This work was supported in part by the Vallely Family Fund and the Mental Retardation and Human Development Program of the Children's Hospital, Boston, MA. a more appropriate model for the study of perinatal events such as intraventricular hemorrhage $(7,20,24)$.

\section{METHOD}

Female New Zealand White rabbits ranging in weight from 2.5 to $3.6 \mathrm{~kg}$ were purchased from commercial vendors and held in isolation for 5 to 7 days before being transferred to the breeding colony. The does were placed in individual cages $(40 \mathrm{H} \times 40 \mathrm{~W}$ $\times 52 \mathrm{D} \mathrm{cm})$ and given access to water, pelleted Rabbit Chow (Ralston-Purina Co., St. Louis, MO) and a salt lick ad libitum. Four to five adult bucks, housed individually in double sized cages $(40 \mathrm{H} \times 80 \mathrm{~W} \times 52 \mathrm{D})$, were used to service the does. The room was kept on a 12-h light-dark cycle, at $23 \pm 1.0^{\circ} \mathrm{C}$ and fresh air was circulated by exhaust fans.

On the day of mating (day 0 ) the doe was transferred to a bucks' cage and intromission was noted visually. To optimize the chance of fertilization the doe was mated sequentially with at least two bucks. Pregnancy could be verified as early as the 7th or 8th day following mating by palpating the uterine horns through the abdominal wall. The doe was kept on the same diet throughout pregnancy.

The litters were delivered by caesarean section 5 to 0 days before term (range 31 to 33 days). On the day of delivery the doe was placed in a restraining box and $50 \mathrm{ml}$ of air was injected rapidly into a marginal ear vein. Death ensued within 15 to 35 s. General anesthetics were avoided because the fetal rabbits either died in utero, failed to initiate spontaneous respiration, or succumbed shortly after birth when general anesthetics were used. Hysterotomy was usually accomplished within 4 to $8 \mathrm{~min}$; the time depending primarily on the size of the litter. After delivery the pharynx of each pup was aspirated and the pups were weighed and coded. To enhance survival newborn rabbits were injected intraperitoneally with $0.2 \mathrm{ml}$ of a $10.8 \mathrm{mM}$ glycerol or glucose solution immediately and again at 4 and at $8 \mathrm{~h}$ after birth. These injections were discontinued after the 1st yr of the study when it became apparent that glycerol administration was not required to enhance the survival of preterm animals fed 
rabbit milk. The pups were then placed in a nest (made of hair clippings obtained from the dam and from wood shavings) kept in a humified Isolet maintained at $35^{\circ} \mathrm{C}$.

The pups were fed orally once a day using a nipple molded from a silastic mixture (Dow Corning Medical Fluid 360, Midland, MI) connected via a polyethylene PE 50 tubing to a 3-ml plastic syringe (without plunger) which contained milk warmed to $38^{\circ} \mathrm{C}$. The height of the syringe relative to that of the pup was adjusted so that milk would flow in response to the animals sucking. During the feeding the pups were swaddled in gauze and held in a supine position. The amount of milk fed the preterm pups was limited to $10 \%$ the body weight. This was equivalent to the daily amount of milk ingested during the first 2 postnatal days by term pups weighed prior to and after being fed by the dam. Initially, the preterm pups were fed a pasteurized milk formula (Charles-River Breeding Lab., Willmington, MA) reported to be nutritionally adequate for newborn rabbits delivered gnotobiotically just before term (12). Subsequently, since the pups failed to thrive on the formula rabbit milk was substituted (3). The milk was obtained from lactating does that were milked two to three times a week between the 1st and 3rd wk postnatally. The doe was separated from its litter overnight prior to being milked the following morning. Normally, the doe was held supine and milk was expressed manually from the teats. The expressed milk was aspirated under vacuum into a plastic bulb (Fischer Scientific, Boston, MA) the open end of which fit over the nipple of the mammary gland. The opposite end of the bulb had been cut and attached to a plastic tube $(0.5 \mathrm{~cm}$ OD $\times$ $50 \mathrm{~cm}$ length) the distal end of which was connected to a $125-$ ml vacuum flask. Approximately 20 to $30 \mathrm{ml}$ of milk could be collected at each milking.

\section{RESULTS}

Most preterm rabbits delivered on the 26th day of gestation, or later, were able to initiate breathing spontaneously. However, all of those delivered on day 26 and over $75 \%$ of those delivered on day 27 of gestation succumbed within the first $6 \mathrm{~h}$ of birth (Fig. 1). In contrast, over $80 \%$ of all pups delivered on gestational day 28 , or later, survived for at least $24 \mathrm{~h}$ (Fig. 1). Older premature pups generally exhibited more vigorous movements, better skin coloration, and were more vocal than the younger ones.

In 25 consecutive litters delivered by hysterectomy at 28 days gestation, and averaging eight pups a litter, a total of 34 deaths

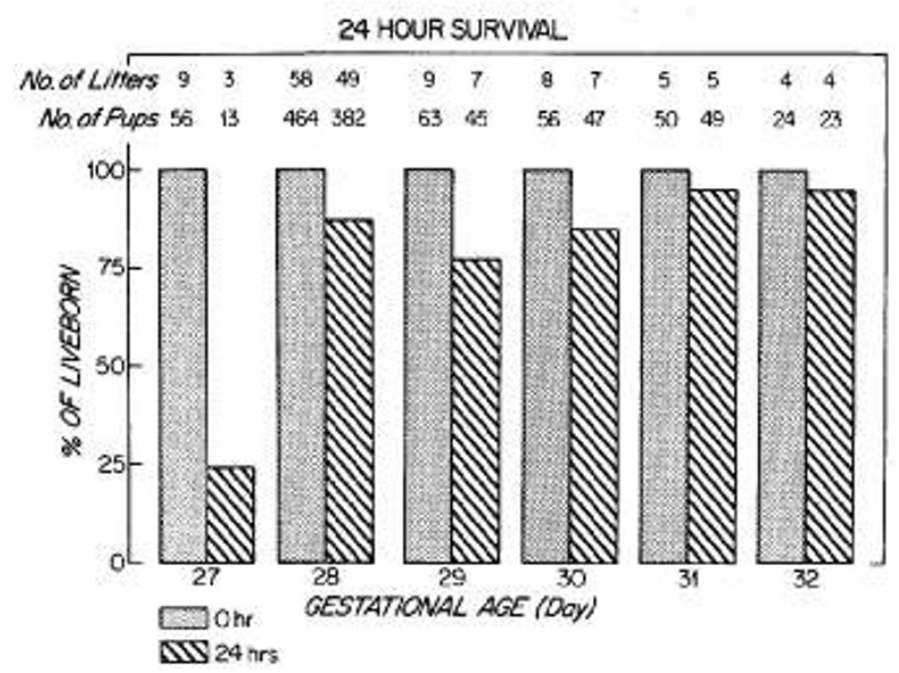

Fig. 1. Survival of rabbit pups $24 \mathrm{~h}$ after ceaesarean delivery at various gestational ages. The number of litters and rabbits are indicated above the bars.

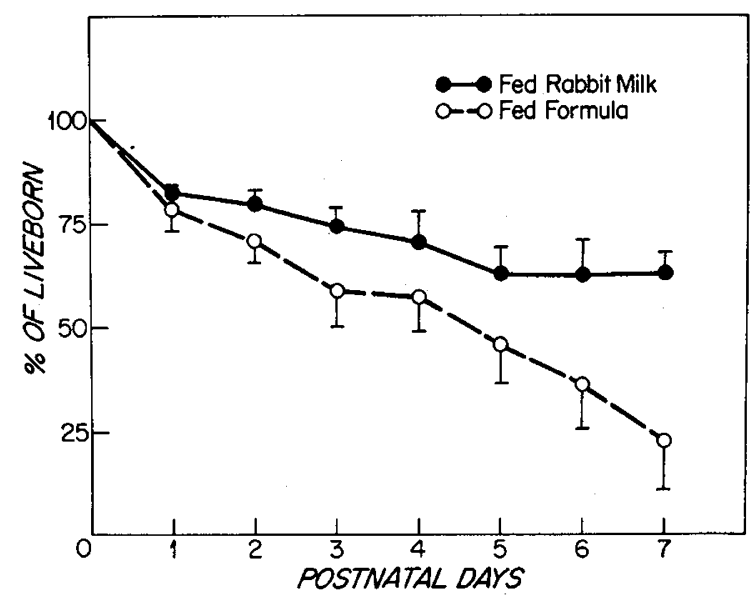

Fig. 2. Postnatal survival of preterm rabbit pups delivered at 28 days gestation fed rabbit milk (solid line) or formula (interrupted line). Values are averages \pm SD.

Table 1. Body wt of newborn preterm and term rabbit pups

\begin{tabular}{lccc}
$\begin{array}{c}\text { Gestational } \\
\text { age (days) }\end{array}$ & $\begin{array}{c}\text { No. of } \\
\text { litters }\end{array}$ & $\begin{array}{c}\text { No. of } \\
\text { pups }\end{array}$ & $\begin{array}{c}\text { Body wt at } \\
\text { birth* }(\mathrm{g})\end{array}$ \\
\hline 26 & 4 & 30 & $27.6 \pm 3.5$ \\
27 & 5 & 36 & $31.9 \pm 3.7$ \\
28 & 77 & 605 & $36.2 \pm 4.2$ \\
$(28 \dagger$ & 26 & 196 & $41.3 \pm 8.0) \ddagger$ \\
29 & 18 & 139 & $40.0 \pm 4.5$ \\
30 & 16 & 117 & $45.6 \pm 5.2$ \\
31 & 10 & 76 & $51.6 \pm 5.5$ \\
32 (term) & 6 & 39 & $56.5 \pm 5.3$ \\
\hline
\end{tabular}

* Values are means and their SDs.

$\dagger$ Pregnant dams bred by a commercial vendor were acquired 5 to 7 days before delivery of the litters.

$¥$ Significantly different from mean body weight of pups delivered at 28 days gestation from dams bred in-house (Student's $t$ test, $p=0.001$ ).

(approximately 17\%) were registered within the first $6 \mathrm{~h}$ of birth. No significant difference in mortality was noted between pups delivered during the first (mortality $18 \%, n=101$ ) and second half (mortality $16 \%, n=101$ ) time intervals of the procedure. However, of the 34 pups that died within the first $6 \mathrm{~h}$ of birth 25 weighed less than the average birth weight $(36.3 \pm 5.3 \mathrm{~g}, n=$ 202) suggesting that in the premature rabbit a relationship exists between mortality and birth weight.

Eighty eight percent of the preterm pups delivered at 28 days gestation and treated with glycerol survived up to $24 \mathrm{~h}$. In contrast, only $16.6 \%$ of the newborn littermates treated with a comparable concentration of glucose were alive at $24 \mathrm{~h}$. Preterm pups fed rabbit milk alone had similar 24-h survival rates as those fed formula and treated with glycerol. Survival could be extended to 7 days and beyond by daily feedings of formula or rabbit milk (Fig. 2).

Birth weights were dependent on gestational age, litter size (Table 1), and surprisingly on whether the doe was bred in-house or by commercial breeders (Table 2). Postnatally, preterm pups fed formula lost more weight and took longer to regain their weight at birth than pups fed rabbit milk (Table 3). Most of the formula fed pups had diarrhea and cultures of innoculates taken under sterile conditions from the stomach and intestine indicated that the gastrointestinal tract of these pups had been colonized by Klebsiella pneumonia, Enterobacter cloacea, Streptococcus fecalis, and Accinobacter anteritas. In contrast, pups fed rabbit milk exhibited little or no diarrhea and maintained a sterile gut.

Preterm pups hand-fed rabbit milk (approximately $10 \%$ of body weight) clearly accrued weight at a significantly slower rate 
than those developing in utero (Table 3). Indeed, 2 days after delivery ( 28 days gestation) the average weight of the preterm pups fed rabbit milk was similar to that reported for undernourished fetal rabbits of equivalent gestational age (29). Attempts to improve weight gain included increasing the amount of milk fed orally and/or by gavage (approximately $20 \%$ of body weight) during the single feeding (two litters) or the implementation of a second oral feeding 6 to $7 \mathrm{~h}$ after the first (two litters). Neither of these two approaches was very successful. Forced feeding of greater amounts of milk resulted in a mortality exceeding $48 \%$ which was unacceptable for establishing the model and milk intake during the 2 nd feeding was generally unimpressive averaging $0.7 \mathrm{ml}$ a pup. In contrast to the seemingly poor postnatal weight gain exhibited by the preterm animal fed rabbit milk the newborn term rabbit fed equivalent amounts of rabbit milk gained weight at rates comparable to that of littermates nurtured by the lactating doe (Fig. 3).

\section{DISCUSSION}

The demise of preterm animals shortly after birth generally has been attributed to the newborn's inability to aerate its lungs (23). The lack of sufficient surfactant in the lungs of the animal born before term is thought to be the primary cause of death

Table 2. Average body wt of litters delivered at 28 days gestation

\begin{tabular}{cccc}
\hline & \multicolumn{2}{c}{ Average wt (g) } \\
\cline { 3 - 4 } $\begin{array}{c}\text { Pups per } \\
\text { litter }\end{array}$ & $\begin{array}{c}\text { No. of } \\
\text { litters }\end{array}$ & $\begin{array}{l}\text { All litters } \\
\text { combined }\end{array}$ & Difference* \\
\hline $\begin{array}{c}\text { a. Bred in house } \\
7\end{array}$ & 10 & $35.9+2.7$ & 9.2 \\
8 & 8 & $33.8+3.2$ & 8.8 \\
9 & 9 & $31.0+3.3$ & 8.0 \\
& & & \\
b. Bred outside & & & 15.3 \\
7 & 6 & $42.2+6.9 \dagger$ & 15.5 \\
8 & 6 & $41.8+5.9 \dagger$ & 17.2 \\
9 & 6 & $40.7+5.7 \dagger$ &
\end{tabular}

* Difference between lightest and heaviest litter of group.

$\uparrow$ Average body weights were significantly different from the mean values of the respective bred in-house groups (Student's $t$ test, $p \leq 0.01$ ).
$(13,17,19)$. However, in most of the above studies lethal concentrations of barbiturates, with or without high concentrations of $\mathrm{KCl}$, were administered to the pregnant doe just prior to delivery (23). Barbiturates are known to reduce blood flow to the uterus of pregnant animals (27) and to cause hypoxia, acidosis, and bradychardia in the fetus (22), and it is just as likely that barbiturate intoxication contributed to the high fetal mortality. This suggestion is supported by the much better survival rates obtained in our study (Fig. 1) as well as in the studies of others (1) in which anesthetics were avoided.

The efficacy of glycerol to enhance and prolong survival of formula-fed preterm rabbits is confirmed herein (Fig. 1). The 24-

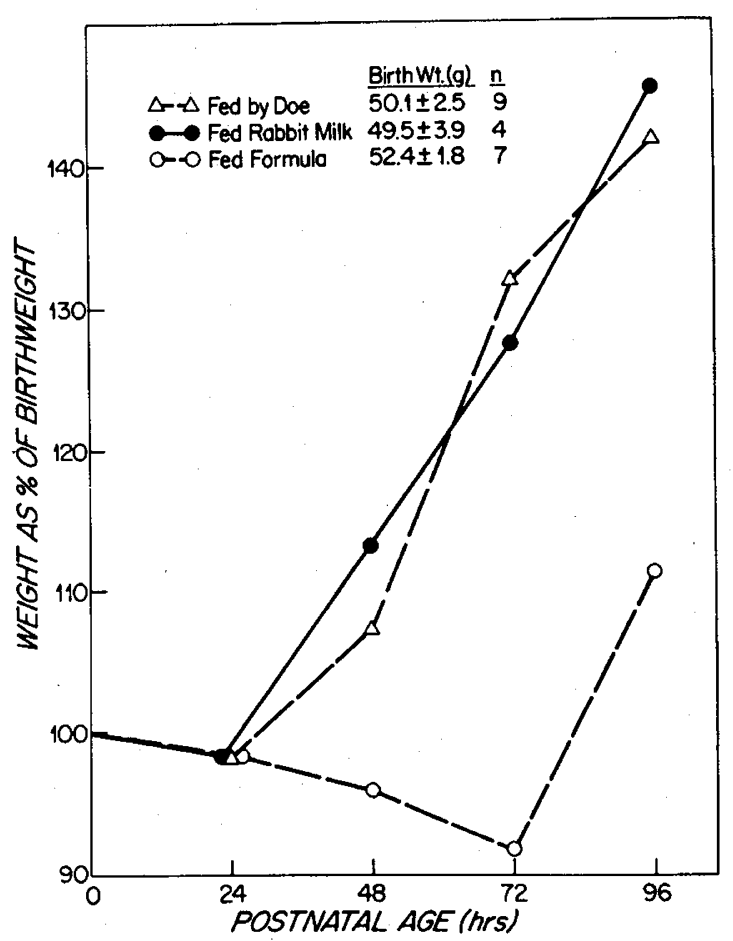

Fig. 3. Postnatal weight gain of term pups hand fed formula, rabbit milk, or fed by the natural doe. Values are averages and bars represent $1 \mathrm{SD}$.

Table 3. Body wt of fetal rabbits developing in utero and ex utero

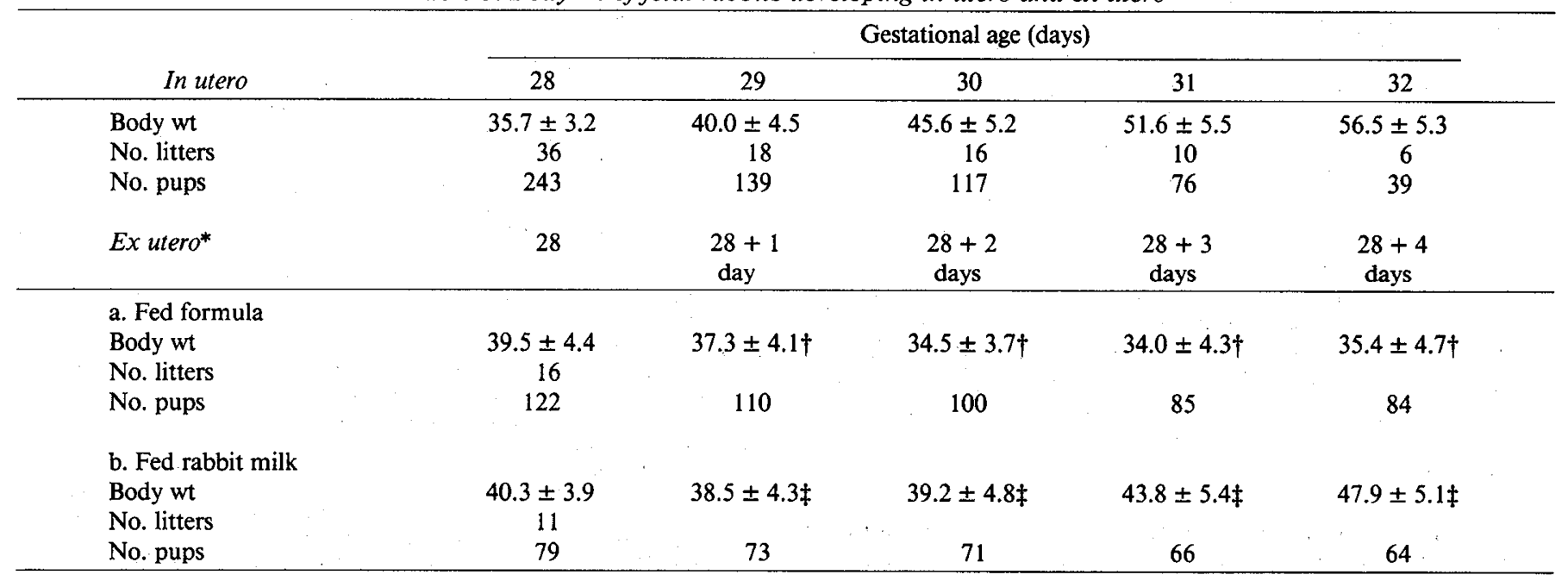

* Only those litters and pups surviving 24 hours or longer were included in these groups.

$\dagger$ Significantly lighter than pups delivered at the equivalent gestational age $(p \leq 0.001$, Student's $t$ test).

$\ddagger$ Significantly heavier than pups of equivalent gestational age fed formula $(p \leq 0.01)$. The amount of formula or rabbit milk fed once daily to each pup was approximately $10 \%$ of the body weight. 
$\mathrm{h}$ rate of survival which averaged $88.8 \%$ in the present study was greater than the $24 \mathrm{~h}$ rate $(48 \%)$ reported by Kotas (18) for preterm pups of the same age and considerably greater than the 12-h postnatal survival (20\%) reported by Coulter et al. (8) for preterm rabbits delivered at 28 days gestation. Kotas (19) suggested that glycerol, which in the preterm rabbit is rapidly converted to phosphatidylcholine, enhanced survival by reducing respiratory insufficiency. However, a second mechanism based on the inability of the preterm rabbit to reverse hypoglycemia and to initiate gluconeogenesis from lactate or alanine has been proposed. Mims (21) suggests that this impairment in carbohydrate metabolism places the animal in jeopardy for energy substrate immediately after birth, particularly if the pup is born with low gycogen stores. Under these circumstances glycerol, but not glucose, serves as an effective substrate. However, glycerol is not necessary in preterm pups fed rabbit milk since its administration to these animals does not further improve survival.

The birth weights shown in Table 1 for newborn preterm rabbits of different gestational ages are similar to those reported by others for preterm rabbits of comparable ages $(12,14)$. Average body weights were related directly to gestational age (Table 1) but inversely to litter size (Table 2). It is not clear why the birth weights of preterm pups delivered at 28 days gestation from does provided by commercial vendors were heavier than those born to does bred in-house. Presumably, as indicated by the wide variability in the average body weights of preterm pups, pregnant does supplied by the commercial vendor must not have been accurately timed for pregnancy and most likely included both younger and older aged litters (Table 2 ).

Whether the slower rate of weight accretion by the preterm rabbit pup maturing outside the uterus is attributable to undernutrition, to excessive fluid loss, or a combination of both is not clear. The fact that newborn preterm and term rabbits fed formula gained less weight postnataly than littermates fed rabbit milk or nurtured by the dam (Fig. 3, Table 3) would suggest that the formula was nutritionally inadequate. However, other factors may be involved since preterm pups delivered and maintained under gnotobiotic conditions have been successfully nurtured when hand-fed similar formulas (12). The results of the present study show that the gastrointestinal tract of newborn preterm and term animals fed formula became colonized and as a consequence most of these animals had diarrhea. Under these conditions it may reasonably be expected that absorption of nutrient from the gut would be compromised and consequently weight gain reduced. Preterm littermates ingesting rabbit milk maintained sterile intestinal tracts, exhibited little or no diarrhea, lost less weight immediately after birth, and regained their birth weight much faster than those fed formula.

Not as readily apparent is the reason for the failure or preterm pups fed rabbit milk to gain weight at rates comparable to their intrauterine counterparts (Table 3). It is possible that the quantity and/or nutritional quality of the rabbit milk fed the preterm pups was inadequate. An estimate of the quantity of milk required by the preterm rabbit to grow at the in utero rate may be derived from the following observations: a) fetal rabbits between 26 to 31 (term) days gestation gain an average of $4.4 \pm 1.2 \mathrm{~g} /$ day $(n=112)$, b) the newborn term rabbit pup requires $3.7 \mathrm{kcal}$ for each gram of weight gained (6); and c) pooled rabbit milk yields $2.07 \mathrm{kcal} / \mathrm{g}(6,28)$. Thus, preterm rabbits require a caloric intake of $16.4 \mathrm{kcal} /$ day $(4.4 \mathrm{~g} /$ day $\times 3.73 \mathrm{kcal} / \mathrm{g})$ or $7.9 \mathrm{ml}$ of rabbit milk/day $(16.4 \mathrm{kcal} \div 2.07 \mathrm{kcal} / \mathrm{g}$ or $\mathrm{ml})$ to achieve a growth rate equivalent to that in utero. This calculated amount of milk, which represents approximately twice the average amount of milk actually consumed by preterm rabbits, may be an overestimate since, in contrast to newborn term animals which from birth are exposed to subthermoneutral temperatures $\left(22\right.$ to $25^{\circ} \mathrm{C}$ ) and must expend some of the caloric intake to maintain body temperature, neither animals in utero nor those in the isolet would be expected to expend as much energy for this purpose. Attempts to feed the preterm pup more milk during the first $48 \mathrm{~h}$ of life were not very successful in improving weight gain during the immediately postnatal period since forced-feeding was associated with a greater mortality and a second feeding proved ineffectual. Possibly the second approach would have been more successful if the two feedings had been spaced further apart.

Even though protein, fat, and caloric content of rabbit milk is many times higher than that of goat, cow, or human milk $(6,9)$, it is possible that rabbit milk from does giving birth to term pups may not be adequate for the preterm animal.

The value of animal models for the study of human disease has long been recognized (2) as has recently the need to develop good animal models for the study of acute and chronic effects of premature birth (24). Poor viability immediately after birth and poor survival thereafter have been the major difficulties encountered in the development of animal models for this purpose. The evidence presented herein indicates that the fetal rabbit delivered before term and fed rabbit milk postnatally will serve this purpose.

Advantages of this animal model include a development of various organ systems relative to birth which parallel that in the infant. For example, brain development of many common laboratory animals during the perinatal period does not parallel that of the human (10). Some species, including the nonhuman primate, are born with central nervous systems that are relatively more mature than that of the newborn infant (11) while others, such as the rodent, are born with relatively less mature brains (11). The lagomorph like the human is classified as a perinatal brain developer (14). Thus, in this respect it may prove to model more accurately perinatal events effecting human brain development than the monkey. Its ready availability, relative inexpensiveness, accuracy in timing pregnancy, and the relatively large size of the newborn and litters constitute practical advantages of the model.

\section{REFERENCES}

1. Aherne W, Dawkins MJR 1964 The removal of fluid from the pulmonary airways after birth in the rabbit, and the effect on this of prematurity and prenatal hypoxia. Biol Neonate 7:214-229

2. Andrews EJ, Ward DC, Alman NH 1979 Spontaneous Animal Models of Human Disease. Academic Press, New York

3. Appel KR, Busse H, Schulz KD, Werner W 1971 Beitrag zur Handaufzucht von gnotobiotischen und SPF-Kaninchen. Z Versuchstierkd 13:282-290

4. Aprile JR, Rulfs J 1976 A convenient neonatal model for developmental studies requiring artificial diets. Biol Neonate 30:109-115

5. Canus-Rodriguez A, Smith WH 1966 The identification of antimicrobial factors of the stomach contents of the suckling rabbit. Biochem J 100:79-82

6. Coates ME, Gregory ME, Thompson SY 1964 The composition of rabbit's milk. Br J Nutr 18:583-586

7. Conner ES, Lorenzo AV, Welch K, Dorval B 1983 The role of intracranial hypotension in neonatal intraventricular hemorrhage. J Neurosurg 58:204209

8. Coulter DM, LaPine T, Gooch M 1984 IVH in the premature rabbit pup: limitations of this animal model. $J$ Neurosurg 60:1243-1245

9. Cowie AT 1969 Variation in the yield and composition of the milk during lactation in the rabbit and the galactopoietic effect of prolactin. J Endocrinol 44:437-450

10. Davison AN, Dobbing $\mathrm{J} 1968$ The developing brain. In: Davison AN, Dobbing $\mathrm{J}$ (eds) Applied Neurochemistry. FA Davies Co., Philadelphia, pp 253-286

11. Dobbing J, Sands J 1979 Comparative aspects of the brain growth spurt. Early Hum Dev 3:78-83

12. Foster HL 1974 Gnotobiology. In: Weisbroth SH, Flatt RE, Kraus AL (eds) The Biology of the Laboratory Rabbit. Academic Press, New York pp 179192

13. Gluck L, Montoyama EK, Smits HL, Kulovich MV 1967 The biochemical development of surface activity in mammalian lung. I. The surface active phospholipids; the separation and distribution of surface-active lecithin in the lung of the developing rabbit. Pediatr Res 1:237-246

14. Harel S, Watanabe K, Linke T, Schain RJ 1972 Growth and development of the rabbit brain. Biol Neonate 21:381-389

15. Hodson WA, Luchtel DL, Kessler DL, Murphy JH, Palmer S, Truog WE, Standaert TA 1979 The immature monkey as a model for studies of bronchopulmonary dysplasia. J Pediatr 95:895-904

16. Kessler DL, Truog WE, Murphy JH, Palmer S, Standaert TA, Woodrum DE, Hodson WH 1982 Experimental hyaline membrane disease in the premature monkey. Am Rev Respir Dis 126:62-69

17. Kikkawe Y, Motoyama EK, Gluck L 1968 Study of the lungs of fetal and newborn rabbits. Morphological, biochemical and surface physical development. Am J Pathol 52:177-209

18. Kotas RV 1976 Glycerol effect on surfactant formation. In: Moore TD (ed) 
Lung Maturation and the Prevention of Hyaline Membrane Disease. Report of the 70th Ross Conference on Pediatric Research. Ross Laboratories, Columbus, $\mathrm{OH}$, pp 37-40

19. Kotas RV, Avery ME 1971 Accelerated appearance of pulmonary surfactant in the fetal rabbit. J Appl Physiol 30:358-361

20. Lorenzo AV, Welch K, Conner S 1982 Spontaneous germinal matrix and intraventricular hemorrhage in prematurely born rabbits. J Neurosurg 56:404-410

21. Mims LC 1979 Adaptive gluconeogenesis in preterm and term rabbits. Pediatr Res 13:241-245

22. Myers RE 1975 Maternal psychological stress and fetal asphyxia: A study in the monkey. Am J Obstet Gynecol 122:47-59

23. Nilsson R 1979 Lung compliance and lung morphology following ventilation in the premature and full term rabbit neonate. Scand J Resp Dis 60:206214
24. Pape KE, Wigglesworth JS 1979 Hemorrhage, Ischemia and the Perinatal Brain. Spastics International Medical Publications, London

25. Reynolds ML, Evans CAN, Saunders NR, Reynolds EOR, Wigglesworth JS 1977 Intracranial hemorrhage in sheep fetus. Pediatr Res 11:1024-1029

26. Ruppenthal GC 1977 Survey of protocols for nursery rearing macaques. In: Ruppenthal GC, Reese DJ (eds) Nursery Care of Nonhuman Primates. Plenum Press, New York, pp 165-185

27. Shnider SM, Biehl DR 1981 The effect of maternal stress and general anesthesia on plasma catecholamines and uterine blood flow in the pregnant ewe. In: Stern L, Salle B, Friis-Hansen B (eds) Intensive Care in the Newborn, III. Massen Publications Inc, New York, pp 31-38

28. Sokal M, Sinclair J 1976 Effect of temperaure on growth of newborn rabbits. Biol Neonate 28:1-11

29. van Marthens E, Harel S, Zamenhof S 1975 Experimental intrauterine growth retardation. Biol Neonate 26:221-231

\title{
Phototherapy for Neonatal Jaundice: in Vivo Clearance of Bilirubin Photoproducts
}

\author{
JOHN F. ENNEVER, ISABELLA KNOX, SCOTT C. DENNE, AND WILLIAM T. SPECK \\ Department of Pediatrics, Rainbow Babies and Childrens Hospital, Case Western Reserve University School of \\ Medicine, Cleveland, Ohio
}

\begin{abstract}
Phototherapy results in the conversion of native bilirubin to more water-soluble configurational and structural isomers. The serum half-life for the configurational isomer, the principal photoproduct in vivo, was determined by high pressure liquid chromatography in six premature infants following cessation of phototherapy. The mean half-life for this isomer was $15 \mathrm{~h}$. The excretion of this isomer, calculated from the measured half-life, is less than half of daily bilirubin production, and therefore cannot account for the total bilirubin elimination observed during phototherapy. The serum concentration of the structural isomer, lumirubin, is lower than that of the configurational isomer; however, excretion is more rapid (serum half-life $<2 \mathrm{~h}$ ). Because of its rapid excretion, lumirubin may be an important pathway for bilirubin elimination during phototherapy. (Pediatr Res 19: 205-208, 1985)
\end{abstract}

\section{Abbreviation \\ HPLC, high pressure liquid chromatography}

Despite the widespread use of phototherapy in the treatment of neonatal hyperbilirubinemia (1), the detailed mechanism by which visible light affects bilirubin metabolism in jaundiced newborns is not known. The purpose of this study was to measure the rate of elimination of the principal bilirubin photoproduct, $4 \mathrm{Z}, 15 \mathrm{E}$-bilirubin, and to determine whether this is sufficient to

Received June 22, 1984; accepted October 3, 1984.

Address correspondence and requests for reprints to John F. Ennever, Ph.D., M.D., Department of Pediatrics, Rainbow Babies and Childrens Hospital, 2101 Adelbert Road, Cleveland, OH 44106.

Supported by the U.S. Public Health service through Grants CA-23692 and Research Career Development Award 1K0-0043 to W.T.S. account for the decline in plasma bilirubin observed during phototherapy.

Bilirubin, derived from the degradation of heme, is a potentially toxic, highly lipophylic molecule. In mammals this pigment is rapidly cleared from the circulation and excreted as a glucuronide conjugate, primarily in the bile (2). Newborn infants commonly develop hyperbilirubinemia due in part to a decreased ability to conjugate bilirubin and an increased pigment load. During phototherapy, the most commonly used treatment for unconjugated hyperbilirubinemia, bilirubin undergoes several reactions (3-7). All of these reactions yield photoproducts which are more polar and therefore presumably more easily excreted than native bilirubin. The fastest photochemical reaction is a $\mathrm{Z}$ to $E$ isomerization reaction $(5,8)$ which in human infants yields primarily the 4Z,15E-bilirubin isomer (6). This reaction is readily reversible and up to $20 \%$ of the total bilirubin can be converted to this isomer during phototherapy $(9-12)$.

Since the quantum yield of the configurational isomerization reaction is at least 40 times greater than that for any other photochemical reaction of bilirubin (8), it has been assumed that the elimination of bilirubin during phototherapy is the result of formation and excretion of this photoproduct. We have used a rapid, quantitative HPLC method (5) to measure the half-life of the configurational isomer in serum of preterm infants undergoing phototherapy. We have found that the rate of elimination of the $4 \mathrm{Z}, 15 \mathrm{E}-$ bilirubin isomer is much slower than previously reported (13) and cannot account for the decline in serum bilirubin observed in infants treated with phototherapy.

\section{METHODS}

Patients. The study population included six premature infants in our level II nursery with a mean gestational age of $30 \mathrm{wk}$ and a mean birth weight of $1.3 \mathrm{~kg}$. All infants were treated with phototherapy from a bank of eight daylight fluorescent lamps 